\title{
Towards the future-proofing of UK infrastructure
}

\section{Tariq Masood PhD}

Senior Research Associate, Distributed Information and Automation Laboratory, Institute for Manufacturing, University of Cambridge, Cambridge, UK; Centre for Smart Infrastructure and Construction, Department of Engineering, University of Cambridge, Cambridge, UK (corresponding author: tm487@cam.ac.uk)

2 Duncan McFarlane PhD

Professor and Head of DIAL, Distributed Information and Automation Laboratory, Institute for Manufacturing, University of Cambridge, Cambridge, UK; Centre for Smart Infrastructure and Construction, Department of Engineering, University of Cambridge, Cambridge, UK
3 Ajith Kumar Parlikad PhD

Senior Lecturer and Deputy Head of DIAL, Distributed Information and Automation Laboratory, Institute for Manufacturing, University of Cambridge, Cambridge, UK; Centre for Smart Infrastructure and Construction, Department of Engineering, University of Cambridge, Cambridge, UK

4 John Dora FICE, FRMetS, CEng, BSC (Hons) CEO, John Dora Consulting Limited, Charlbury, UK

5 Andrew Ellis

Asset Management Programme Manager, Heathrow Airport, London, UK

6 Jennifer Schooling PhD

Director, Centre for Smart Infrastructure and Construction, Department of Engineering, University of Cambridge, Cambridge, UK
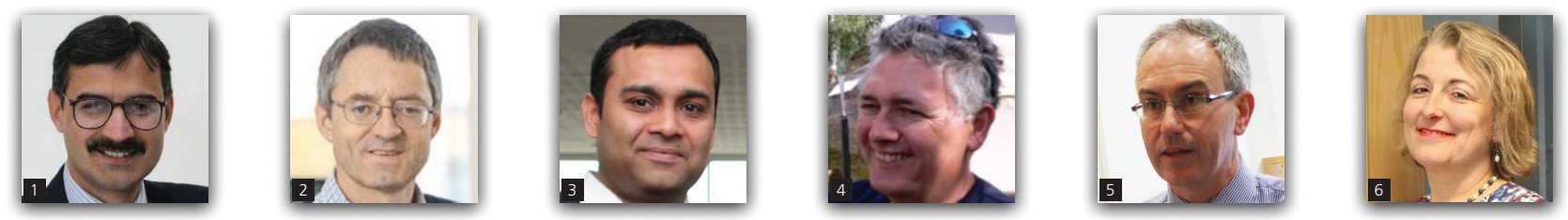

Ensuring long-term performance from key infrastructure is essential to enable it to serve society and to maintain a sustainable economy. The future-proofing of key infrastructure involves addressing two broad issues: (i) resilience to unexpected or uncontrollable events (e.g., extreme weather events); (ii) adaptability to required changes in structure and/or operations of the infrastructure in the future. Increasingly, infrastructure owners, designers, builders, governments and operators are being required to consider possible future challenges as part of the life cycle planning for assets and systems that make up key infrastructure. A preliminary study is reported here that aimed at exploring the following questions related to infrastructure (systems): what does 'future-proofing' of infrastructural assets mean? Why and when should critical infrastructure be future-proofed? How can infrastructure assets (systems) be prepared for uncertain future events? How can future-proofing considerations be incorporated into infrastructure asset management practices? To seek answers to the above questions, two industrial workshops were conducted that brought together leading practitioners in the UK infrastructure and construction sectors, along with government policymakers. This paper captures lessons learnt from the workshops and proposes a framework for linking future-proofing into asset management considerations. Case studies of Dawlish railway and Heathrow airport are also presented.

\section{Introduction}

The aim of this paper is to explore the 'what, why and how' of infrastructure future-proofing - ensuring that a nation's infrastructure is fit for the future in addition to satisfying current needs. Infrastructure assets have long service lifetimes and are therefore subject to a range of 'disruptions' over time such as extreme weather events, changes of use and ageing. Identification of such disruptions and developing a strategy for mitigating the risks of such disruptions through effective asset management processes is essential for long-term sustainability of infrastructure systems. Although there is widespread agreement among practitioners about the need to address this, there is a lack of a structured, common approach for considering the changing future needs of infrastructure as part of their asset management plans. To help industry move towards this goal, this paper proposes a framework for infrastructure future-proofing, which includes a set of criteria that can be used for assessing the level of future-proofing in existing infrastructure systems. The framework was developed through a number of case studies and by conducting two industrial workshops bringing together leading practitioners in the UK infrastructure and construction sectors, along with government policymakers.

To begin, this paper presents an overview of infrastructure futureproofing and the need to consider the future-proofing of infrastructure assets. Following this, the paper covers general issues and views on how to future-proof infrastructure and some future-proofing strategies 
currently in use in the infrastructure sector and their implications. A framework is proposed for assessing the future-proofing requirements of infrastructure, including a set of criteria for future-proofing assessment. The framework is supported by examples from two case studies. Key barriers to infrastructure future-proofing are presented. Finally, the International Organization for Standardization (ISO) 55001 Asset Management standard is examined to highlight the interplay between future-proofing and infrastructure asset management and the value of future-proofing over the life cycle of an asset is discussed. In addressing these key questions, the paper aims to clarify the role of future-proofing in the management of key infrastructure.

\section{What is infrastructure future-proofing?}

Future-proofing is the process of anticipating future events, changes, needs or uses to prepare appropriately, minimise impact and capitalise on opportunities (Godfrey and Savage, 2012). Other related terms used in the context of future-proofing are 'obsolescence management' (Romero Rojo, 2011; Romero Rojo et al., 2009), 'reconfigurability' (Koren et al., 2013) and 'digital preservation' (CCSDS, 2012; Barbau et al., 2014). Shetty (2014) defined future-proofing in an asset management context as 'the process of anticipating the distant future and taking actions to minimise risks and maximise opportunities for value realisation from assets'. The term 'future-proofing' has also been used for long-term business continuity (ISO, 2012) and long-term information continuity (Masood et al., 2013).

In this paper, infrastructure future-proofing is defined as 'the process of making provision for future developments, needs or events that impact on particular infrastructure through its current planning, design, construction, operation and maintenance processes'. Essentially, infrastructure future-proofing involves the consideration of future disruptions in the asset management systems of the organisations responsible for infrastructure management.

There are generally two major dimensions of infrastructure futureproofing: infrastructural resilience - resilience to unexpected/ uncontrollable events and circumstances; and change management capability - capability to adapt or respond to changing needs, uses or capacities.

\section{Infrastructural resilience}

In simple terms, this property refers to the ability of the infrastructure to maintain/resume normal operations during/after an adverse event. This might include ability to withstand climate change variations, flooding events or even terrorist actions. This addresses sustainable asset longevity and asset management for future revenue - that is, developing resilience to emerging risks and liabilities as well as resilience against disruptions.

\section{Adaptability and change management capability}

Flexibility to adapt to an unexpected and uncertain future means changing the way of building by allowing for future growth and capacity requirements (considering dimensions of capacity, suitability, usability and desirability that contributes towards achieving future-proofing). This also means building or managing a business to avoid/reduce the impact of future change events and taking account of future drivers (climate, carbon dioxide, resources and population) in decision-making in advance. Examples of future-proofing in this context include a capacity upgrade of an underground train station, easier reuse of substructure elements and buried structures and allowing infrastructure life to be extended through capacity changes such as adding extra lanes to a bridge or building more floors on an existing building.

These definitions of infrastructure future-proofing are applicable to a wide scope of infrastructure including transport, energy, water and communication. However, because of the nature of the organisations engaged in this study, this paper is more focused on transport infrastructure (rail, road and highway networks including structures, e.g. bridges and tunnels; mass transit systems; railways; airports, etc.).

\section{Why consider future-proofing of infrastructure?}

It is a significant commitment to consider future-proofing and take appropriate actions which increase the level of future-proofing of key infrastructure. Three key issues that motivate the need to future-proof infrastructure are

- ageing infrastructure and long operational lifetimes

- extreme weather events

- capacity enhancements and changing uses of key infrastructure.

Other reasons for future-proofing include risk reduction and reduced effort in redesign, redevelopment, reconstruction or demolition with diminishing government budgets, reduced life cycle costs, changes in legislation - for example on carbon dioxide footprints and recognising opportunities for future exploitation. Wider social, economic and environmental benefits of future-proofing are also important for infrastructure with high vulnerability and lower capacity to respond to risks (Godfrey and Savage, 2012). These issues capture some of the evolving debates around the need for anticipating and managing future scenarios for critical infrastructure carefully and thoroughly. In resolving these key issues, to do so also needs to make economic sense by measuring and quantifying the value of potential disruption to a company's operation. Each of the three key issues will now be explored in detail.

\section{Ageing infrastructure and long operational lifetimes}

Infrastructure assets generally have long operational lifetimes. For instance, much of the UK's existing infrastructure was originally built in the nineteenth century - for example London's sewerage system and the Royal Albert Bridge over the River Tamar (Defra, 2011). The national infrastructure has recently been assessed (ICE, 2014) and was mostly found to be 'in need of attention' or 'at risk', with the exception of strategic transport (e.g. rail) and water infrastructure, which were considered to be 'adequate for 
now'. No major infrastructure category was graded as 'fit for the future'.

HM Treasury has recently identified planned investment needs in excess of $£ 375$ billion to replace ageing assets and those assets that do not comply with EU regulations, to help meet policy commitments (e.g. climate change targets) to support economic growth and to meet the future needs of a growing population (House of Commons 2014; Waller, 2014). To achieve the investment goals, the national infrastructure plan was first published in 2010 and is regularly updated every year since then (HM Treasury, 2010, 2013, 2014; Waller, 2014).

\section{Extreme weather events}

Climate and weather are changing globally. UK has recently faced a range of extreme weather events (e.g. flooding, wind and snowstorms and drought). Such natural hazards account for $10-35 \%$ of all delays or service interruptions to electricity, road and rail infrastructure (Committee on Climate Change, 2014; DfT, 2014a; IPCC, 2001, 2014).

During 2009-2014, severe flooding in the UK caused a number of road bridges to collapse and disrupted the airports, road and rail infrastructure (DfT, 2014a; HM Government 2011). Well over a thousand major roads and over a thousand further railway assets are located in areas of significant chance of flood risk (Environment Agency, 2009) (Figure 1).

The Intergovernmental Panel on Climate Change (IPCC) has predicted increasingly dramatic weather changes in the future, which highlights the need for infrastructure to be designed and maintained keeping future climate variations in mind (IPCC, 2001, 2014).

These challenges are also increasingly being recognised by transport providers. Network Rail and the rail industry are keen to learn how climate change will affect their ability to achieve and deliver a safe railway, a highly reliable railway and increased capacity and value for money (DfT 2014a; Network Rail, 2010). Network Rail's Tomorrow's Railway and Climate Change Adaptation programme has identified heating- and flood-related impacts on safety, performance and likely negative impact from climate change (Avery, 2014; Dora, 2014; Network Rail, 2010; RSSB, 2011).

Similarly, London's transport network has a number of areas that have the potential to be affected by weather-related events - for example flooding, overheating, low temperatures and snow (TfL, 2015a). Transport for London conducted a Business Climate Change Risk Assessment exercise in 2011 (TfL, 2015a) and the results suggest that there are many weather-related risks that fall under medium to very high impact but very low likelihood. Crossrail has also identified key climate change impacts as increased flooding (fluvial, tidal and pluvial or surface water), high temperatures (extreme weather events) and increased water scarcity (Paris, 2011; TfL, 2015a).

\section{Capacity enhancements and changing uses of key infrastructure}

Anticipated or unanticipated user-driven changes to the loading of infrastructure and infrastructure systems are also expected to occur over long infrastructure life cycles, necessitating significant modifications to assets. The consequences of such disruptions and changing requirements are significant over long infrastructure life cycles.

For instance, problems at Heathrow due to winter snowstorms during the winter of 2010-2011 were compounded by the lack of spare or contingency capacity at the airport as it already operated to its maximum every day (UK Parliament, 2011). At present, Heathrow is planning to expand its capacity by reconfiguring its terminals. A number of capacity upgrade projects are being undertaken for underground stations in London - for example

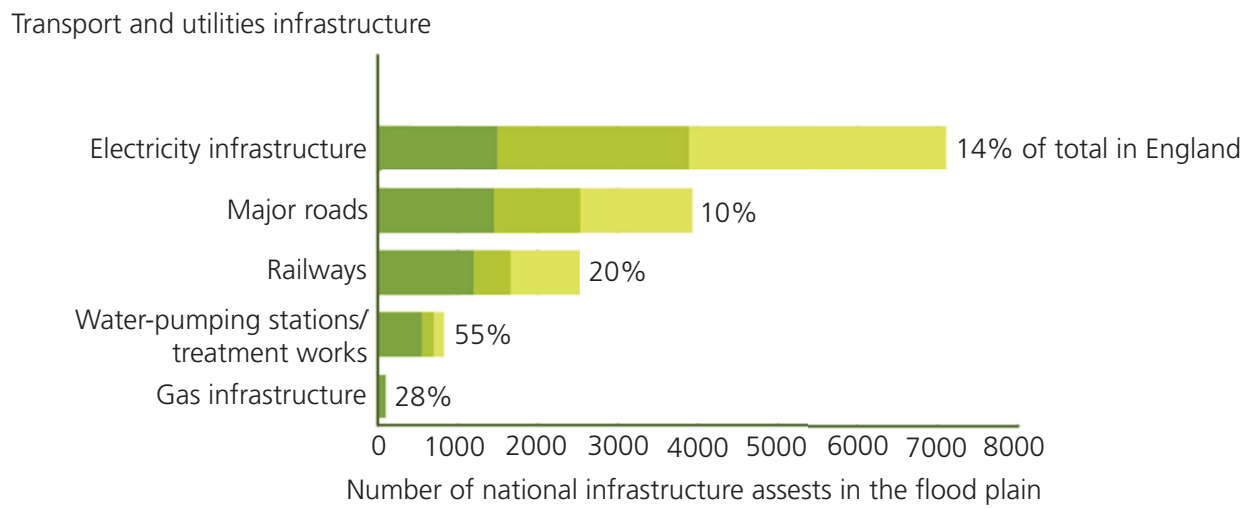

Significant chance Moderate chance Low chance

Figure 1. National transport and utilities infrastructure assets in

flood risk areas (Environment Agency, 2009) 
Bond Street, Tottenham Court Road and Bank/Monument underground stations (worth hundreds of millions of pounds) (TfL, 2015b). London's rail capacity is also being enhanced by building Crossrail (Europe's largest infrastructure project worth $£ 14 \cdot 8$ billion) (Crossrail, 2015).

Land use changes and user-driven future changes to infrastructure and infrastructure systems also need to be considered. Examples include Canary Wharf redevelopment and changing modes of use of buildings - for example warehouse to residential conversion or change of a residential block into an office building or vice versa. The consequences of such disruptions and changes over long infrastructure life cycles are potentially significant. However, there has been very little systematic understanding of the benefits and costs of providing flexibility at design stage to incorporate future growth and change (Fawcett, 2011).

When developing strategies for future-proofing infrastructure assets against the aforementioned disruptions, organisations need to also consider the socio-economic and behavioural impact of those actions and their wider implications. For instance, would constructing another lane of the M25 just increase the demand and result in the need for further lanes? Such behaviours are a result of complex interrelationships between organisational strategies, government policies and various other factors, making them hard to predict. However, identifying the possible scenarios and including them in the assessment process would be beneficial.

\section{Barriers to infrastructure future-proofing}

Figure 2 identifies a number of the key barriers to infrastructure future-proofing with key elements noted in each of the categories (Masood et al., 2014). In the figure the barriers have been categorised into key areas. Clearly if the economic value of future-proofing was clearer, other barriers would be reduced.
The identified barriers to future-proofing highlight the need to take action in this regard. The key actions will be based on enhancing understanding of the concepts - for example establishing a common terminology and meaningful metrics for future-proofing. Another action will be to enhance communication and introduce effective feedback loops between different stakeholders, for example feeding back knowledge from operators/maintainers to designers to inform future-proofing design decisions. Stronger business cases for infrastructure future-proofing are also required. Steps need to be taken to align investment rules with whole life thinking as well as raising awareness levels across industry on future-proofing issues. These actions need to be taken with a shared responsibility among government, industry and other stakeholders.

\section{How to future-proof infrastructure?}

The growing set of drivers for a more formal and considered approach to managing the future of critical infrastructure naturally leads to the question of how infrastructure can be future-proofed. To a certain extent, companies already future-proof, using a number of strategies for assessing and managing non-civil assets and systems across life cycle stages. These strategies are summarised in Figure 3, which represents the outputs from an industrial future-proofing workshop, literature and a series of interviews with practitioners (see the Acknowledgements for the list of companies involved). The figure classifies future-proofing strategies according to whether they are design related or management related ( $x$ axis) and whether they are focused on individual assets or at the system level ( $y$ axis). For example, obsolescence forecasting is used in the aerospace and defence sectors at the design stage as well as through life for dealing with long-life products and services (Romero Rojo, 2011).

Future-proofing-related strategies relevant for civil infrastructure assets and systems partially overlap with those used for non-civil

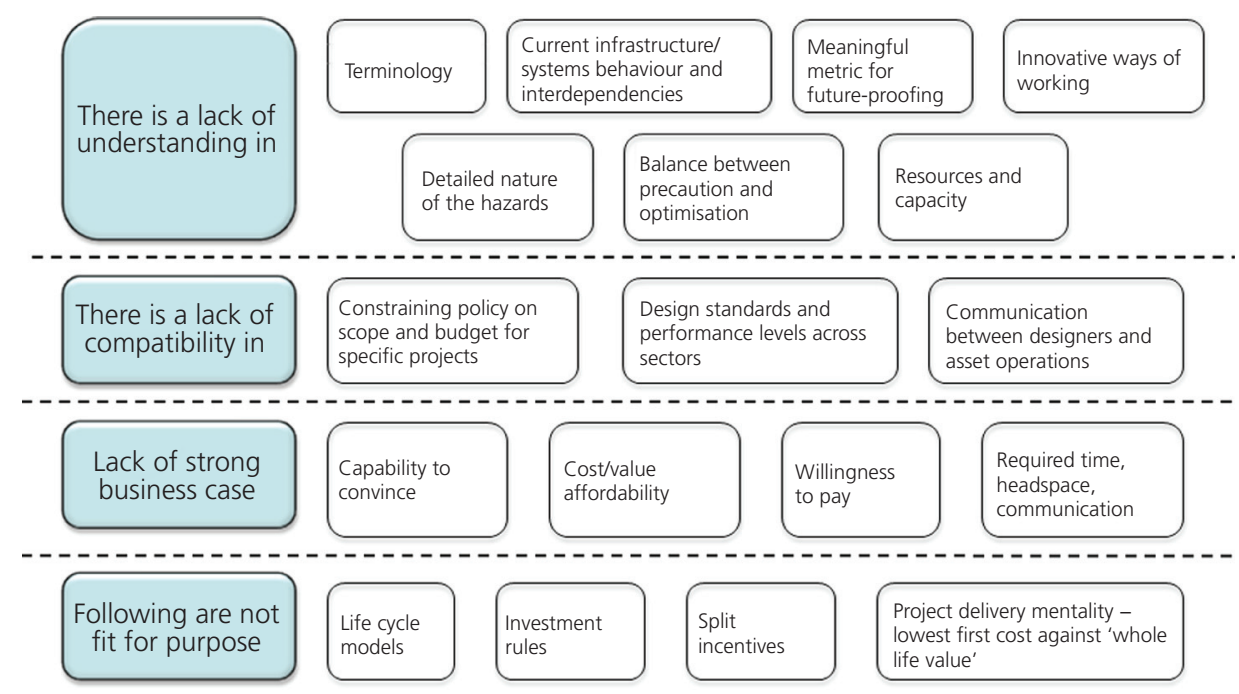

Figure 2. Key barriers to infrastructure future-proofing (Masood

et al., 2014) 


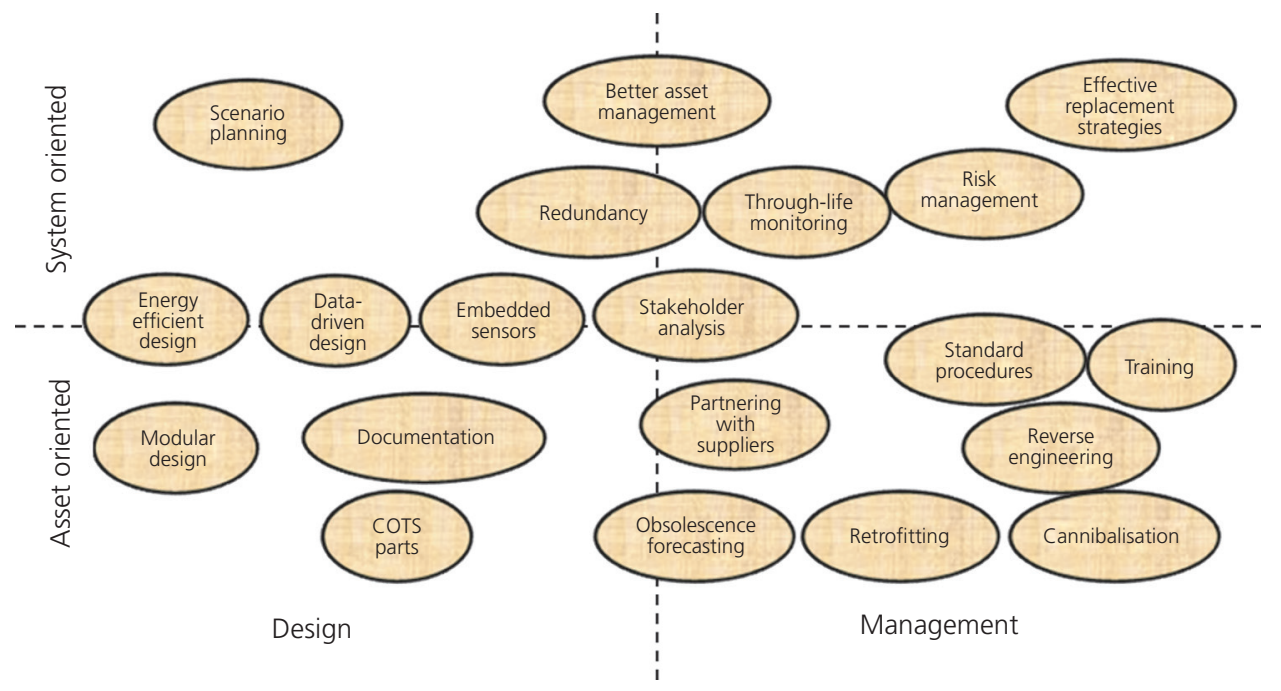

Figure 3. Future-proofing strategies for industrial assets and systems. COTS: commercial off-the-shelf

assets and systems. For example, Heathrow considers future issues while conducting its overall master planning exercises in the following areas: runway capacity, stand capacity, terminal capacity, surface access and infrastructure such as heating, cooling, power, aircraft fuel systems, drainage, communications and information technology and baggage (Ellis, 2014). Some organisations carry out long-term scenario planning and robust decision-making techniques while also considering strategic growth and resilience of the network capacity, security and climate change views (e.g. Atkins's future-proofing cities project; Godfrey and Savage, 2012).

Other future-proofing strategies used for infrastructure assets and systems include improving decision support tools, developing strong governance processes, working with and influencing asset owners and policymakers on ensuring efficient planning and design of interconnected infrastructure assets, preparing climate change adaptation plans by way of conducting feasibility studies and investing in sustainability and energy-monitoring capability enhancement.

However, it emerges from discussions with related organisations that there is a lack of a structured, common approach for considering the changing future needs of infrastructure as part of its asset management plans. Current approaches miss the opportunity to consider and assess infrastructure future-proofing at a system level (Dora, 2014; McBain 2014). Moreover, unexpected asset failures may also be partly due to a lack of systematic consideration of future infrastructure scenarios during earlier life cycle stages (e.g. planning and design).

\section{A structured framework for considering infrastructure future-proofing}

In this section a systematic approach to infrastructure futureproofing is proposed. It is proposed that, as a minimum, the following should be considered when considering future-proofing of infrastructure (see Figure 4)

- conducting requirements analysis

- analysing current infrastructure management practice

- identifying and analysing future-proofing considerations

- identifying and analysing key issues related to a futureproofing strategy

- developing a model for future-proofing-considered infrastructure management.

These elements represent a potential pathway to establishing future consideration as part of an overall infrastructure asset management plan.

For each of the elements of the framework proposed in Figure 4, key issues will now be identified and, as a conclusion, the remaining key steps will be identified to consolidate these requirements into a usable framework.

To illustrate the approach being proposed, two case studies will be used to exemplify the framework where appropriate: Dawlish railway and Heathrow airport. These cases have been selected because of the very different future challenges they face. In the case of Dawlish railway, the key issue is the need for resilience in the face of environmental events, while Heathrow's challenges are more concerned with the rapidly changing needs of its customers and the growth of the industry generally.

Network Rail's 4-mile-long Dawlish sea wall is actually a series of wall sections of different construction forms, running from Teignmouth through Dawlish to Langstone Rock at the western tip of Dawlish Warren. Along this stretch, parts of the walls are separated by tunnels. The walls have been maintained on a 


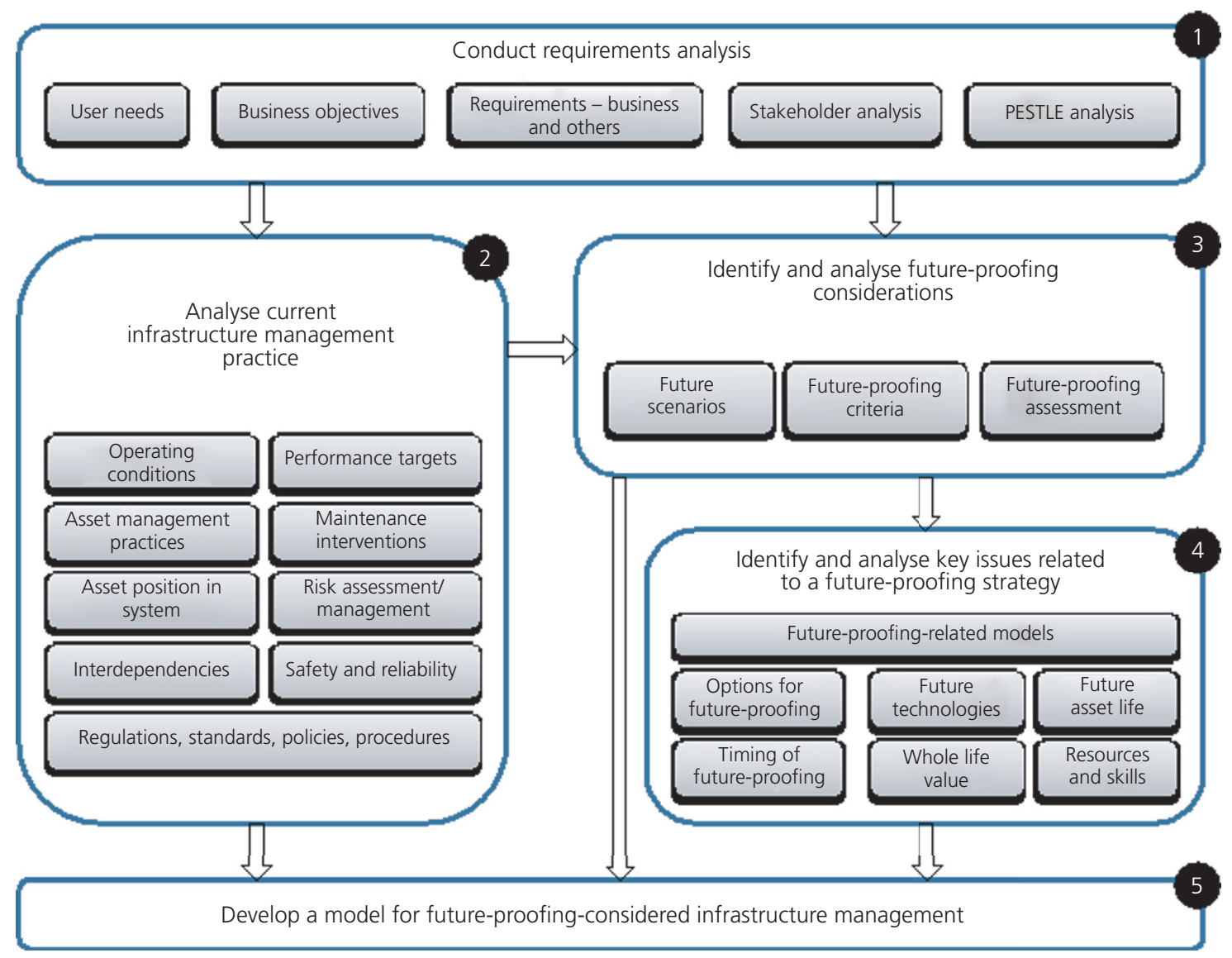

Figure 4. A framework for future-proofing of infrastructure portfolio. PESTLE: political, economic, social, technological, legal and environmental

basically reactive basis for at least the past 30 years with the only recent investment being in the early 2000s when around $£ 10$ million was spent on forming a concrete toe along the base of the wall, which has served to increase the wall's resistance to undermining. The sea wall has suffered from major failures in the past but none as serious as the $80 \mathrm{~m}$ breach on 4 February 2014 due to wind and the sea's high tide washing away ballast and the foundations on which the track is built (DfT, 2014a).

Taking about 8 weeks to repair and accompanied by numerous other failures, damage to the station at Dawlish and serious geotechnical failure of the cliffs above the line near Teignmouth and the storms over the winter of 2013-2014 have brought into question the future of the sea wall and the resilience of this portion of the Great Western main line that serves much of Devon and is the only line connecting Cornwall with the rest of the country. These require spending roundly $£ 600000$ per annum maintaining the Network Rail-owned sea and estuary walls between Exeter, Newton Abbot and Exmouth (Network Rail, 2014a).

The Heathrow airport case study provides insights into futureproofing at the airport, which needs to consider a wide range of variables that will, or might, change in the future. Political, economic, environmental and technological factors all need to be factored into decisions about how to future-proof the ongoing development of the airport.

\section{Conduct requirements analysis}

Initially, a detailed (future) requirements analysis is needed. During this stage, user needs and requirements (business and external) must be identified by conducting political, economic, social, technological, legal and environmental analysis and stakeholder analysis (e.g. UK government, regulators, public, investors, media and legal bodies).

The requirement to provide a service connecting Exeter with stations between Exeter and Newton Abbot is enshrined in the First Great Western franchise and Network Rail's operating licence set out by the Office of Rail Regulation and the Department for Transport by way of the Railways Act provisions (Network Rail, 2009). These provisions are reviewed and confirmed within the 5-year regulatory cycle (DfT, 2014b).

The Rail Safety and Standards Board (RSSB) (2008) showed how climate change-induced sea-level rise and increased storminess 
will impact the Dawlish railway. Dawson (2012) reinforced this by examining disruptions, damages, repairs and wider economic consequences for the southwest.

The development of utilities infrastructure at Heathrow airport requires thinking about the long-term plan and growth of the airport and future-proofing to ensure that the infrastructure will meet those requirements. An example of this is the management of the airport's high-voltage electrical network, where there is a longterm plan to create a network that offers both improved resilience and increased capacity. This is then being built incrementally as the need for additional electrical demand arises or when there is a need to undertake work on the network in a particular area. Without a future-proofing plan the network would be developed in a way that would be unsustainable, with individual projects simply installing infrastructure to meet their needs to reduce cost but not in a way that enables ongoing improvement.

\section{Analyse current infrastructure management practice}

To understand the future-proofing problem of an infrastructure, it is important to analyse the current infrastructure management practice (in other words the ability of an infrastructure to respond to the present day let alone future requirements) - for example the current operating conditions, current performance targets, current asset management practice, asset position in system, interdependencies, regulations, standards, policies and procedures, safety and reliability, risk assessment and maintenance interventions.

If a particular infrastructure community has issued a sector-specific or a group-of-infrastructure level guidance, those would be useful at this stage. For example, the Cabinet Office (2013a) provides a summary of the 2013 sector resilience plans for nine national infrastructure sectors: communications, emergency services, energy, finance, food, government, health, transport and water.

Network Rail traditionally maintains its sea defences in Devon on a rolling programme of masonry repointing and a find-and-fix policy where minor defects are repaired before they become hazardous. While the sea wall complex in itself affords protection to the Dawlish railway, prevents erosion of the soft sandstone cliffs and protects Dawlish town from the full force of the sea, it is not particularly effective at resisting wave overtopping onto the railway tracks or onto trains; after a 2008 study by RSSB into climate change impacts, Network Rail planned to design replacement infrastructure for the railway during Control Period 5 (2014-2019) with a construction planned for Control Period 6 (2019-2024) (Network Rail, 2014a; RSSB, 2008).

The RSSB study determined that in the baseline year (2006) the line would be affected by climate change-related closures on a 1in-5 year basis. By the 2080s this would become a 1-in-1 year probability (RSSB, 2008).

Heathrow airport has carbon dioxide reduction targets and is regularly reviewing ways to minimise its environmental impact.
The way Heathrow has chosen to heat and cool their buildings using a district heating and cooling approach with networks fed by centralised boilers or chillers as opposed to individual buildings having their own heating and cooling plant allows Heathrow to plug in alternative greener energy sources and helps future-proof opportunities to introduce alternative energy sources more simply.

In terms of economic factors, one of the most significant is trying to future-proof against changes in airline ownership (e.g. purchase of British Midland by British Airways in 2012). Changes in ownership are far easier to accommodate when operating from large terminal buildings that host a larger number of airlines, hence the gradual move to an airport operating with fewer larger terminals.

\section{Identify and analyse future-proofing considerations}

The next step is to identify possible future disruptions, develop a set of future-proofing criteria and conduct future-proofing assessment.

\section{Identify and analyse future scenarios of possible disruptions in infrastructure management}

Infrastructure operating environments are subject to a range of potential future changes. A number of events might occur in future; therefore, it is important to identify possible event scenarios - for example flood, snow and wind. Potential usage changes/upgrades also need to be considered early on. Evaluating possible future scenarios will help asset owners to make informed decisions to prepare the infrastructure to cope with disruptions and impacts of future events and changes.

The future operating environment through climate change was shown to be disruptive to the economy of the southwest and for rail operations generally; delays and closures south of Exeter can have impacts across the network. Annual closures and frequent speed restrictions and single-line working procedures would mean an unacceptable level of resilience for the Dawlish railway.

This knowledge of possible future scenarios does help to prepare the owners, the operators and the government for likely decisions to future-proof this important part of the railway system. Dawson (2012) has shown a relationship between sea-level change and maintenance activity along the sea defences on the London-Penzance railway line.

The predictions on how the climate will change have led to Heathrow airport changing their asset design standards for building services and drainage to reflect predicted increases in temperature and increases in rainfall. New facilities are designed in accordance with the new standards and existing facilities have been reviewed so that they understand where the operation might be at risk.

\section{Identify and contextualise criteria for future-proofing assessment}

It is crucial to understand and assess the fitness for the future of the infrastructure based on the current infrastructure state, future 
scenarios (e.g. in light of environmental change, future events or usage change), performance targets and a set of robust futureproofing criteria. This is in line with identifying and assessing specific risks as well as impacts of not future-proofing a particular infrastructure. This will help in identifying gaps and taking further actions to enable future-proofing of infrastructure as well as developing and analysing future business cases.

The following set of future-proofing criteria is proposed.

- (C1) Resilience is the ability to withstand shocks and recover quickly. The UK government's approach to building infrastructure resilience is based on its definition as 'the ability of assets and networks to anticipate, absorb, adapt to and recover from disruption', where resilience is secured through a combination of principal components - that is, resistance, reliability, redundancy and response and recovery (Cabinet Office, 2011, 2013a, 2013b, 2015).

- (C2) Adaptability is the ability of infrastructure to readily adapt or reconfigure if understanding of risks or requirements changes over time. Adaptability is often defined as having different dimensions: extension, internal, use and planning (Cowee and Schwehr, 2012).

- (C3) Replaceability is the ability to be replaced during or at the end of infrastructure life or use, assuming that the infrastructure has a finite life.

- (C4) Reusability is the ability of the infrastructure to be reused or extended at the end of its life. Even though extension is partially used in adaptability, where it is executed during the operation phase, in reusability, extension is meant to be at the end of asset life.

- (C5) System stability is the ability of infrastructure assets to work for an overall balanced or positive effect, ensuring stability of a system or systems during or after future change(s). This could also mean that systems should work with, rather than against, natural processes (McBain, 2014).

Information future-proofing is very important for decision-makers, for a 'system-of-systems' view, for future owners, operators, the environment and the society. Hence, it is important to identify through-life information requirements at earlier life cycle stages of infrastructure and ensure availability of information at all stages by planning and taking appropriate actions for its collection, retention and reuse in the long term (Masood et al., 2013). The principles outlined here deserve a lot more emphasis due to their importance and should be considered as a criterion for infrastructure future-proofing; however, these are not included in detail as this paper is focused on future-proofing of physical infrastructure. Masood et al. $(2013,2015)$ may be consulted for further details on information future-proofing.

To successfully incorporate future-proofing into asset management processes, organisations would need to consider the above elements in their strategies to plan, design, construct, maintain and retire infrastructure. Organisations need to interpret these guiding criteria for a particular infrastructure, identify their importance to their organisations and assets (in some cases, some of these criteria may not be important at all), assess the current state and then work to achieve required future-proofing goals. The key criteria for future-proofing were allocated weightings during one of the project workshops, where the participants from 17 companies prioritised the criteria in terms of relevance to future-proofing in their organisations (see the Acknowledgements for the list of companies involved). The polling results are presented in Figure 5.

The order of future-proofing criteria elements presented in Figure 5 may change from organisation to organisation. This would serve

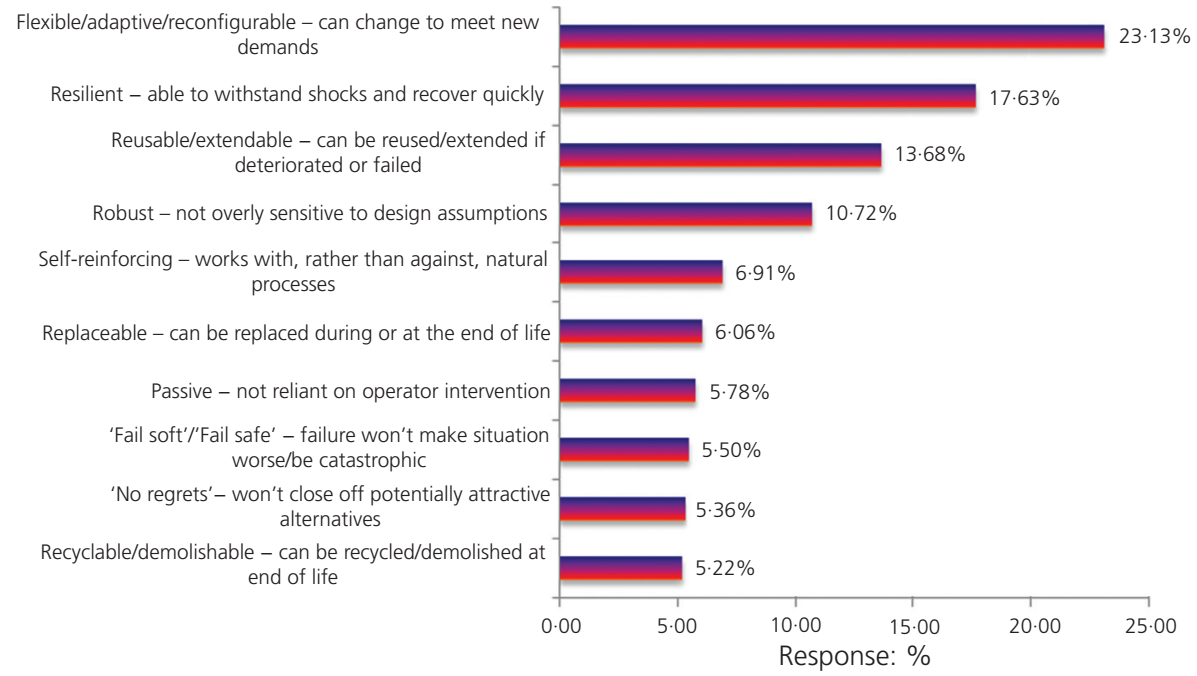

Figure 5. Infrastructure future-proofing criteria - responses from participants of future-proofing project workshop 
as a guide as to where it is important for an organisation to focus attention. It should be noted that the aim is not to achieve $100 \%$ against all of the criteria. This should be examined on a case-bycase basis and the desired level against each criterion must be identified.

Once future-proofing criteria are contextualised according to a specific infrastructure, various possible future scenarios for the infrastructure are assessed against the future-proofing criteria, prior to consideration of appropriate future-proofing strategies.

\section{Identify and analyse key issues related}

\section{to a future-proofing strategy}

It is vital to identify and analyse key issues to be addressed as part of a future-proofing strategy. The following questions will help in identifying and analysing such issues related to a futureproofing strategy.

What future-proofing models and strategies are relevant for an infrastructure?

What are the options for future-proofing?

- What future technologies are relevant and going to impact on an infrastructure?

- Why invest in such technologies?

- How can such technologies be used in future-proofing the infrastructure?

- How are asset lives being affected?

- What is the best timing for future-proofing?

- What is the whole life value in future-proofing?

- Would the organisation have the right resources and skills in place when future-proofing actions are required?

The Dawlish railway has had to undertake extensive work over the last year to restore the southwest's rail connection and make the line more resilient for the future. This was accomplished by the following (Network Rail, 2014b)

- cliff stabilisation work between Teigmouth and Dawlish

- fully restoring signalling and electronic equipment

restoring and improving the public footpath on the sea wall to enable residents to use it at high tide, which was not possible before.

This work was in response to the severe damage caused by very strong winds and high seas during February 2014 to the railway line that runs through Dawlish, washing away a section of the sea wall, $80 \mathrm{~m}$ of track, platforms at Dawlish station and sections of the coastal path.

Where Heathrow airport can anticipate that there will be changes in types of technology or changes in the amount of demand, they can consider future-proofing for this. Two examples of this are firstly Heathrow's hold baggage-screening systems, where it is known that the technology will continue to evolve and become more sophisticated, so Heathrow designs its baggage-handling facilities with sufficient flexibility in terms of space, access and service capacity to easily allow upgrades of screening machines.

Secondly, Heathrow recognised early on that the demand for wireless technology would increase dramatically and that this would impact both airport operational services and the quality of service for passengers if allowed to develop without strict controls. Future-proofing to ensure an efficient use of limited radio spectrum through the use of shared infrastructure for wireless systems such as phones and wireless devices ensures that the spectrum that is available at the airport is used most effectively by all.

Future-proofing at the airport is undertaken in number of ways, responding to diverse factors that shape how the airport will operate and be used by airlines and passengers in the future.

Based on the aforementioned steps, it is important to form a model for future-proofing-considered infrastructure management. This is discussed in the following section.

\section{Develop a model for future-proofing-considered infrastructure management}

Based on the process described in the previous subsections, a model for future-proofing-considered infrastructure management has been developed (see Figure 6). Based on previous steps of the future-proofing framework, assessment of infrastructure futureproofing is conducted by way of future-proofing criteria. The model reviews possible future scenarios against future-proofing criteria to see if the current infrastructure capabilities are adequate or need to be enhanced. This informs as well as helps improve existing infrastructure management practices.

Some examples of what infrastructure future-proofing assessment against infrastructure management would contain are included in the following.

- To what extent is an underground railway infrastructure resilient in the face of environment changes (e.g. increasing heat on tracks)?

- To what extent is a rail infrastructure resilient in the face of disruptions due to, for example, flood, snow and wind?

- To what extent are underground stations in London adaptable in the face of increasing usage demands?

- To what extent are current (sub)assets replaceable in the face of (the possibility of) significant failures necessitating such replacements?

- To what extent are piles reusable when converting an office block to a large residential building or vice versa, in a congested place in London?

- To what extent are other transport-related systems going to be affected if changes to underground station systems are made in response to increase in user demands?

- To what extent are current asset management practices applicable in the face of (the possibility of) significant disruptions/future scenarios? 


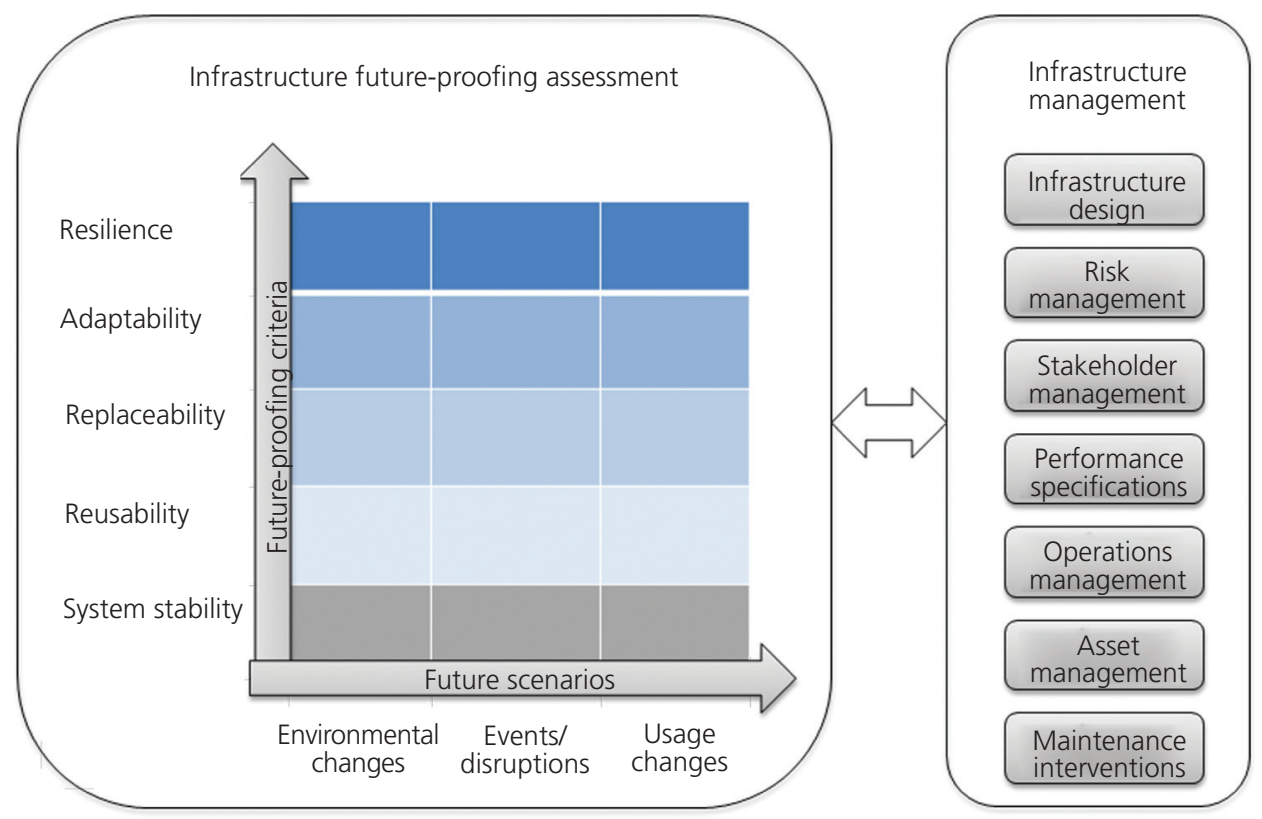

Figure 6. Model for future-proofing-considered infrastructure management

- To what extent are current performance targets for key infrastructure applicable in the face of environment changes/ future scenarios?

The following are the key criteria to form a model for futureproofing-considered infrastructure management of the Dawlish railway.

- Resilience - The Dawlish railway needs to withstand increased stormy weather and sea-level rise to afford reliable railway traffic. The damage caused to the Dawlish railway during February 2014 due to stormy weather and the extensive restoration work in response provides an example of the importance of building resilience in overall futureproofing of this railway section.

- Adaptability - If affordability is a concern, the sea wall complex could be rebuilt with a height commensurate with wave heights expected until, say, the 2050s, and then it could be raised higher. Passive provision could be made economically by constructing foundations large enough to accommodate a higher and/or wider wall.

- Replaceability - The wall could be constructed in a modular way, allowing extension or replacement with less difficulty than its traditional, masonry construction currently allows. Indeed, there is talk in the railway industry of a long-term planning process of widening (triple or quadruple tracks) the railway - a modular approach could permit this to happen at a future date.

- Reusability - This is the ability of the infrastructure to be reused or extended if deteriorated or failed - again a modular approach can aid reusability.
- System stability - A rock-armour protection approach can help this but is likely to be unappealing to the local community due to its harsh visual impact on an amenity coastline famous for its beaches.

It is also considered at Heathrow airport that a model for futureproofing-considered infrastructure management should include key criteria elements of resilience, adaptability, replaceability, reusability and system stability, as discussed in the following.

- Resilience - The changes in hold baggage system and wireless technology at the airport in advance provide examples of the role of key future-proofing criteria in Heathrow's model. It is important to consider how resilient the hold baggage system would be in the face of various disruptions in future, such as power cuts affecting the baggage system, leaving thousands of passengers having to fly without their luggage.

- Adaptability - Another example is from Heathrow's long-term planning for new terminals incorporating a model that considers key future-proofing elements (e.g., adaptability and resilience).

- Replaceability - Adopting a modular approach for the baggage handling system is one of the approaches to consider for enabling replaceability of some components in case of failure.

- Reusability - Again, a modular approach helps in reusing some of the components where possible.

- System stability - How a new airport terminal could affect other transportation networks (e.g., road and rail networks) is also an important consideration to be made part of a model for future-proofing-considered infrastructure management of an airport organisation. 
The model for future-proofing-considered infrastructure management can be further enhanced to map impacts of future scenarios and potential future-proofing strategies against performance, operations, asset management or maintenance of infrastructure assets.

An integrated approach to dealing with future-proofing considerations and asset management practice is vital for success. This is further discussed in the following.

\section{Integrating future-proofing considerations with asset management practice}

Future-proofing should be integrated with asset management practice to gain the most value. Treating future-proofing as a stand-alone requirement leads to marginalisation of the issue and ultimately to future-proofing becoming an add-on consideration. Hence, it is important that future-proofing concepts are aligned with asset management practice and standards. Here some steps are identified towards integrating future-proofing into a broader infrastructural asset management agenda.

Based on discussions during the future-proofing project workshops with the industry, the following actions will help in integrating future-proofing considerations with asset management practice

- Addressing stakeholder requirements at an early stage

- Adopting standardised approaches to future-proofing

- Establishing and implementing criteria for future-proofing infrastructural assets across asset life cycle stages to help assess current state of future-proofing and take necessary actions to keep on future-proofing agenda

- Planning for change earlier on, allowing for future growth across life cycle stages and managing change in operations to help in building resilience and adaptability

- Keeping future-proofing goals at the core of organisational policies, strategies, tactics and operations during the whole life cycle of infrastructure

Integration can also be supported by developing (non-prescriptive) standards, establishing benchmarks and codes of practice, understanding the value of future-proofing and defining/identifying impact (benefits for funding and costs for not funding). Government input can be critical here, through legal and regulatory standards and guidance. Key stakeholders in this process include but are not limited to - the public, asset owners/operators/ maintainers and organisations (e.g., utility companies, all industry bodies, interdependent/mutually benefiting companies and Infrastructure UK).

There are synergies between future-proofing concepts and asset management standard, ISO 55001:2014 (ISO, 2014). The following clauses of ISO 55001 can be extended to include requirements for future-proofing (Shetty, 2014).

- Clause 4.1 (understanding the organisation and its context) can include future-proofing requirements and future-proofing criteria.
- Clause 4.2 (understanding the needs and expectations of stakeholders) can also include future-proofing requirements and future-proofing criteria.

- Clause 6.1 (actions to address risks and opportunities) can include future-proofing requirements and long-term risks and opportunities.

- Clause 6.2 (asset management objectives and plans to achieve them) can include future-proofing criteria and a model for future-proofing-considered infrastructure management.

Finally, when considering how future-proofing might be integrated into current asset management practices, it is worth noting that future-proofing will impact differently at different stages in an asset's life cycle. The greatest value of future-proofing is created at earlier asset life cycle stages; however, that value is usually accrued at later stages in the asset's life. The following describes the value accrued at different asset life cycle stages and the futureproofing actions which can be taken at each stage.

- The requirements and planning stage can provide value in terms of greater certainty, answers to more questions, more long-term options, attractive financial proposition and greater rates of return. Actions can include defining asset life and specifying future requirements.

- The designing/building/installing stage is a stage in an asset's life cycle for future-proofing that provides negligible value gain. However, actions taken at this stage can provide significant value later on. Actions include adding capacities, functionalities and redundancies to assets and tailor designing to asset life.

- The operating stage can provide value in terms of reliable performance of infrastructure and cheaper infrastructure operations.

- The maintaining/renewing/upgrading stage can provide value in terms of less reactive maintenance, safer planning and scheduling. Actions can incorporate predicting and preventing failures; predicting and proposing interventions.

- The decommissioning/reusing stages can provide greater residual value. Actions at this stage include improving ability to decommission safely and in an environment-friendly way and extracting or extending maximum effective life based on evidence.

\section{Conclusions}

Due to long lifetimes and service requirements of infrastructure assets, developing an effective strategy to future-proof infrastructure to ensure long-term sustainability and value delivery is essential. This paper has highlighted the key issues surrounding the issue of infrastructure future-proofing, explaining its importance, the major challenges and strategies that can be considered to future-proof infrastructure assets.

The paper describes two major dimensions of infrastructure futureproofing - developing resilience to unexpected/uncontrollable 
Infrastructure Asset Management

Volume 3 Issue 1
Towards the future-proofing of UK

infrastructure

Masood, McFarlane, Parlikad et al. events and circumstances and ensuring the capability to adapt or respond to changing needs, uses or capacities.

Infrastructure future-proofing is challenging due to the following issues: recognizing increased levels of investment in economic infrastructure and demands for value for money; developing and delivering best practice and innovation; identifying appropriate time horizons; identifying key stakeholders and decision-makers; balancing long-term risks against near-term need; identifying sponsors; capacity building; and making a business case.

The paper finds that the most value of future-proofing is accrued in the maintaining/renewing/upgrading life cycle stage of the infrastructure, while other life cycle stages can support accrual of value during these stages. This highlights the importance of including long-term needs and disruptions when designing infrastructure assets, as the extra investment put in at the design stage may pay off later during usage, especially in cases where changes to the assets may become more costly and involve heavy user disruptions. Nevertheless, a good business case needs to be made to ensure that the right amount (and the right kind) of investment is made.

To support this analysis, the paper presents a framework for infrastructure future-proofing, which includes a set of criteria that can be used to assess each asset in terms of its level of futureproofing. It is, however, important to note that each organisation needs to evaluate these criteria against the needs of each asset (or asset type) and identify the level of achievement that is necessary against each criterion. Even though this research has considered a wide spectrum of industries, it is worth investigating whether additional criteria need to be included as part of this analysis as the needs of individual organisations and assets might differ.

Most importantly, the paper recommends that future-proofing considerations must be included as part of the organisation's asset management system. Future-proofing and asset management are not separate functions; there must be an integrated approach. The role of key stakeholders, including governments, regulators and standards organisations, is vital in addressing most of the challenges and integrating future-proofing in asset management practices.

\section{Acknowledgements}

The authors would like to acknowledge the Centre for Smart Infrastructure and Construction (CSIC), the Engineering and Physical Sciences Research Council (Grant EP/K000314/1), Innovate UK and the industrial partners, which collectively funded this project. The authors are thankful to the CSIC industrial partners involved in the future-proofing project. The authors are also thankful to the speakers and delegates from London Underground, Costain, University College London, International Business Machines (IBM), Crossrail, John Dora Consulting, Heathrow, Cementation Skanska, Ciria, Network Rail,
Arup, Highways Agency, Atkins, Halcrow/CH2M, Lang O' Rourke, Lend Lease, Infrastructure UK, the Committee on Climate Change and CSIC, who attended the CSIC workshop(s) on infrastructure future-proofing. The authors are also thankful to the following companies who responded to the questionnaire on future-proofing strategies for industrial assets and systems: ABB, BAE Systems, Boeing, Caterpillar, EA Technology, ExxonMobil, Finning, Hitachi, IBM and Rolls-Royce.

\section{Data statement}

There is no real data to share for this paper.

\section{REFERENCES}

Avery K (2014) Climate change adaptation and rail. 1st CSIC Workshop on Infrastructure Futureproofing. Cambridge, UK. CSIC (Centre for Smart Infrastructure and Construction) and Institute for Manufacturing, Cambridge, UK.

Barbau R, Lubell J, Rachuri S and Foufou S (2014) Towards a reference architecture for archival systems: use case with product data. Journal of Computing and Information Science in Engineering 14(3): 1-12, http://dx.doi.org/10.1115/1.4027150.

Cabinet Office (2011) Keeping the Country Running: Natural Hazards and Infrastructure. Cabinet Office, London, UK. See https://www.gov.uk/government/uploads/system/uploads/ attachment data/file/61342/natural-hazards-infrastructure.pdf (accessed 22/12/2014).

Cabinet Office (2013a) A Summary of the 2013 Sector Resilience Plans. Cabinet Office, London, UK. See https://www.gov.uk/ government/uploads/system/uploads/attachment_data/file/ 271370/SRP_Public_Summary_2013.pdf (accessed 22/12/2014).

Cabinet Office (2013b) Resilience in Society: Infrastructure, Communities and Business. Cabinet Office, London, UK. See https://www.gov.uk/guidance/resilience-in-societyinfrastructure-communities-and-businesses (accessed 22/12/2014).

Cabinet Office (2015) National Risk Register of Civil Emergencies. Cabinet Office, London, UK. See https://www. gov.uk/government/uploads/system/uploads/attachment_data/ file/419549/20150331_2015-NRR-WA_Final.pdf (accessed 15/04/2015).

CCSDS (Consultative Committee for Space Data Systems) (2012) OAIS: Reference Model for an Open Archival Information System, Recommendation for Space Data System Practice. CCSDS, Washington, DC, USA. CCSDS 650.0-M-2, Magenta Book. See http://public.ccsds.org/publications/archive/ 650x0m2.pdf (accessed 14/08/2013).

Committee on Climate Change (2014) Managing Climate Risks to Well-Being and the Economy. Committee on Climate Change, London, UK. Adaptation Sub-Committee Progress Report. See https://www.theccc.org.uk/wp-content/uploads/ 2014/07/Final_ASC-2014_web-version.pdf (accessed 28/10/2014).

Cowee NP and Schwehr P (2012) The Typology of Adaptability in Building Construction. Lucern School of Engineering and 
Infrastructure Asset Management

Volume 3 Issue 1
Towards the future-proofing of UK

infrastructure

Masood, McFarlane, Parlikad et al.
Architecture, Competence Centre for Typology and Planning in Architecture, vdf Hochschulverlag AG an der ETH Zürich, Zurich, Switzerland, pp. 1-110.

Crossrail (2015) Crossrail in Numbers. See http://www.crossrail. co.uk/news/crossrail-in-numbers (accessed 20/01/2015).

Dawson DA (2012) The Impact of Sea-Level Rise on the LondonPenzance Railway Line. PhD thesis, University of Plymouth, Plymouth, England. See http://hdl.handle.net/10026.1/912 (accessed 03/05/2014).

Defra (Department for Environment, Food and Rural Affairs) (2011) Climate Resilient Infrastructure: Preparing for a Changing Climate. Defra, London, UK. See www.defra.gov. uk/environment/climate/sectors/infrastructure-companies/ (accessed 21/01/2015).

DfT (Department for Transport) (2014a) Transport Resilience Review - a Review of the Resilience of the Transport Network to Extreme Weather Events. DfT, London, UK. See https://www.gov.uk/government/uploads/system/uploads/ attachment_data/file/335115/transport-resilience-review-web. pdf (accessed 22/01/2015).

DfT (2014b) Great Western Specification Consultation. DfT, Rail Executive, London, UK. See https://www.gov.uk/government/ uploads/system/uploads/attachment_data/file/309926/gwconsultation-document.pdf (accessed 25/01/2015).

Dora J (2014) Futureproofing and asset management. 2nd CSIC Workshop on Infrastructure Futureproofing, Cambridge, UK. CSIC, Cambridge, UK.

Ellis A (2014) Heathrow - future proofing of infrastructure. 1st CSIC Workshop on Infrastructure Futureproofing, Cambridge, UK. CSIC, Cambridge, UK.

Environment Agency (2009) Flooding in England: A National Assessment of Flood Risk. Environment Agency, Bristol, UK.

Fawcett W (2011) Investing in flexibility: the lifecycle options synthesis. Projections - The MIT Journal of Planning 10: $13-29$.

Godfrey N and Savage R (2012) Future Proofing Cities: Risks and Opportunities for Inclusive Urban Growth in Developing Countries. Atkins, Epsom, UK. See http://r4d.dfid.gov.uk/ Output/191840/ (accessed 15/01/2015).

HM Government (Her Majesty's Government) (2011) Climate Resilient Infrastructure: Preparing for a Changing Climate. Department for Environment, Food and Rural Affairs, London, UK. See https://www.gov.uk/government/uploads/system/ uploads/attachment_data/file/69269/climate-resilientinfrastructure-full.pdf (accessed 10/01/2015).

HM Treasury (Her Majesty's Treasury) (2010) National Infrastructure Plan. HM Treasury, London, UK.

See https://www.gov.uk/government/uploads/system/uploads/ attachment_data/file/188329/nip_2010.pdf (accessed 24/10/2014).

HM Treasury (2013) National Infrastructure Plan. HM Treasury, London, UK. See https://www.gov.uk/government/uploads/ system/uploads/attachment_data/file/263159/national infrastructure_plan_2013.pdf (accessed 24/10/2014).
HM Treasury (2014) National Infrastructure Plan. HM Treasury, London, UK. See https://www.gov.uk/government/uploads/ system/uploads/attachment_data/file/381884/2902895 NationalInfrastructurePlan2014_acc.pdf (accessed 05/01/2015). House of Commons (2014) Infrastructure Investment: The Impact on Consumer Bills. Committee of Public Accounts, London, UK. Fifth Report of Session 2014-15. See http://www. publications.parliament.uk/pa/cm201415/cmselect/cmpubacc/ 406/406.pdf (accessed 28/10/2014).

ICE (Institution of Civil Engineers) (2014) The State of the Nation Infrastructure 2014. ICE, London, UK. See https://www.ice. org.uk/ICEDevelopmentWebPortal/media/Documents/Media/ Policy/State-of-the-Nation-Infrastructure-2014.pdf (accessed 06/01/2015).

IPCC (Intergovernmental Panel on Climate Change) (2001) Climate change 2001: the scientific basis. In Contribution of Working Group I to the Third Assessment Report of the Intergovernmental Panel on Climate Change (Houghton JT, Ding Y, Griggs DJ et al. (eds)). Cambridge University Press, Cambridge, UK.

IPCC (2014) Summary for policymakers. In Climate Change 2014: Mitigation of Climate Change - Contribution of Working Group III to the Fifth Assessment Report of the Intergovernmental Panel on Climate Change (Edenhofer O, Pichs-Madruga R, Sokona Y et al. (eds)). Cambridge University Press, Cambridge, UK, pp. 1-32. See https://www. ipcc.ch/pdf/assessment-report/ar5/wg3/ipcc_wg3_ar5_ summary-for-policymakers.pdf (accessed 26/10/2014).

ISO (International Organization for Standardization) (2012) ISO 22301: Business continuity management systems requirements. ISO, Geneva, Switzerland.

ISO (2014) ISO 55001: Asset management - management systems - Requirements. ISO, Geneva, Switzerland.

Koren Y, Hu SJ, Gu P and Shpitalni M (2013) Open-architecture products. CIRP Annals - Manufacturing Technology 62(2): 719-729, http://dx.doi.org/10.1016/j.cirp.2013.06.001 (accessed 15/01/2015).

Masood T, Cuthbert R, McFarlane DC and Parlikad AK (2013) Information futureproofing for large-scale infrastructure. Proceedings of the IET/IAM Asset Management Conference. IET (Institution of Engineering and Technology), London, UK.

Masood T, McFarlane D, Schooling J and Parlikad AK (2014) The role of future proofing in the management of infrastructural assets. International Symposium for Next Generation Infrastructure. Vienna, Austria, pp. 147-152. See http://discovery.ucl.ac.uk/1469416/1/Final\%20Proceedings.pdf (accessed 03/08/2015).

Masood T, Yilmaz G, McFarlane DC and Parlikad AK (2015) An Information Futureproofing Approach for Large-Scale Infrastructure. University of Cambridge, Cambridge, UK.

McBain W (2014) Futureproofing infrastructure for disruptive events: flooding. 1st CSIC Workshop on Infrastructure Futureproofing, Cambridge, UK. CSIC, Cambridge, UK. 
Infrastructure Asset Management

Volume 3 Issue 1
Towards the future-proofing of UK

infrastructure

Masood, McFarlane, Parlikad et al.
Network Rail (2009) Route 12 - Reading to Penzance, Route Plans 2009. Network Rail, London, UK. See http://www. networkrail.co.uk (accessed 16/12/2014).

Network Rail (2010) Network Rail Interim Climate Change Adaptation Report. Network Rail, London, UK.

See http://www.climatesoutheast.org.uk/images/uploads/ Network Rail_ARP report.pdf (accessed 16/12/2004).

Network Rail (2014a) Network Rail's Delivery Plan for Control Period 5. Network Rail, London, UK. See http://www. networkrail.co.uk/publications/delivery-plans/control-period-5/ cp5-delivery-plan/ (accessed 15/12/2014).

Network Rail (2014b) Dawlish. Network Rail, London, UK. See http://www.networkrail.co.uk/timetables-and-travel/stormdamage/dawlish/ (accessed 16/12/2014).

Paris R (2011) Crossrail - Climate Change Adaptation. Crossrail, London, UK. Crossrail presentation. See https://www.google. co.uk/url? sa $=\mathrm{t} \& \mathrm{rct}=\mathrm{j} \& \mathrm{q}=\& \mathrm{esrc}=\mathrm{s} \&$ source $=$ web $\& \mathrm{~cd}=1 \& \mathrm{cad}=$ rja\&uact $=8 \&$ ved $=0$ ahUKEwif-4642ODJAhUEuhQKHZ09B KgQFggdMAA\&url=http\%3A\%2F\%2Fwww.ciht.org.uk\% 2Fdownload.cfm\%2Fdocid\%2F57418A21-CFEC-4501-93139 ED2F9CAA141\&usg=AFQjCNHine9rCDnEUYnKDtoPNSn _M329PA (accessed 28/12/2014).

Romero Rojo FJ (2011) Development of a Framework for Obsolescence Resolution Cost Estimation. PhD thesis, Cranfield University, Cranfield, UK. See http://dspace.lib. cranfield.ac.uk/handle/1826/6854 (accessed 05/12/2014).

Romero Rojo FJ, Roy R, Shehab E and Wardle PJ (2009) Obsolescence challenges for product-service systems in aerospace and defence industry. Proceedings of the 1st Industrial Product-Service Systems (IPS2) Conference. Cranfield, UK. See http://hdl.handle.net/1826/3845 (accessed 05/12/2015).
RSSB (Rail Safety and Standards Board) (2008) Impact of Climate Change on Coastal Rail Infrastructure. RSSB, London, UK. T643 Research Brief. See http://www.rssb.co.uk/library/ research-development-and-innovation/research-brief-T643.pdf (accessed 07/12/2014).

RSSB (2011) Operations and Management: Adapting to Extreme Climate Change (TRaCCA), Phase 3 Report - Tomorrow's Railway and Climate Change Adaptation. RSSB, London, UK. T925 Report. See http://www.rssb.co.uk/Pages/researchcatalogue/T925.aspx (accessed 02/12/2014).

Shetty N (2014) ISO 55001 framework for futureproofing. 2nd CSIC Workshop on Infrastructure Futureproofing, Cambridge, UK. CSIC, Cambridge, UK.

TfL (Transport for London) (2015a) Providing Transport Services Resilient to Extreme Weather and Climate Change - 2015 Update Report Following Last Report to Government in 2011. Transport for London, London, UK. See https://www.gov.uk/ government/uploads/system/uploads/attachment_data/file/ 466602/climate-adrep-tfl.pdf (accessed 20/10/2015).

TfL (2015b) Improving the Tube - What We're Doing. Transport for London, London, UK. See https://tfl.gov.uk/ campaign/tube-improvements/what-were-doing (accessed 20/01/2015).

UK Parliament (2011) Impact on Transport of Recent Adverse Weather Conditions - Written Evidence from British Airways (AWC 31). UK Parliament, London, UK. See http://www. publications.parliament.uk/pa/cm201011/cmselect/cmtran/ uc794-ii/awc31.htm (accessed 20/10/2014).

Waller K (2014) Futureproofing in asset management. 2nd CSIC Workshop on Infrastructure Futureproofing, Cambridge, UK. CSIC, Cambridge, UK.

\section{WHAT DO YOU THINK?}

To discuss this paper, please submit up to 500 words to the editor at journals@ice.org.uk. Your contribution will be forwarded to the author(s) for a reply and, if considered appropriate by the editorial panel, will be published as a discussion in a future issue of the journal. 